\title{
Assistência em saúde às crianças e adolescentes abrigados em Ribeirão Preto, SP
}

\author{
Health care to children and adolescents sheltered in Ribeirão Preto, SP
}

Atención en salud a los niños y adolescentes abrigados en Ribeirão Preto, SP

\author{
Maria das Graças Carvalho Ferriani', Aline Paiva Bertolucci', Marta Angélica lossi Silva' \\ 'Universidade de São Paulo, Escola de Enfermagem de Ribeirão Preto. Ribeirão Preto, SP
}

Submissão: 06/08/2007

Aprovação: $21 / 01 / 2008$

\section{RESUMO}

O presente artigo tem como objetivo descrever a assistência em saúde oferecida às crianças e adolescentes abrigados no Centro de Atendimento à Criança e ao Adolescente Vitimizados (CACAV), no município de Ribeirão Preto-SP. O estudo é descritivo e exploratório. Os dados foram coletados mediante entrevista semi-estruturada, observação não estruturada e análise documental. Os pontos Que investigamos foram as estruturas de recursos humanos e do espaço físico do abrigo e a assistência em saúde prestada pelo abrigo e pela unidade de saúde de referência. Observamos muitas deficiências, cujas soluções não dependem apenas do abrigo, mas sim de uma articulação com outros setores, buscando uma assistência em saúde de Qualidade, Que contemple as necessidades das crianças e adolescentes em sua integralidade.

Descritores: Violência doméstica; Crianças; Adolescentes; Institucionalização; Saúde.

\section{ABSTRACT}

This article aims to describe the health care offered to children and adolescents sheltered at the Care Center for Child and Adolescent Victims, in Ribeirão Preto-SP, Brazil. The study is descriptive and exploratory. Data were collected through semistructured interview, non-structured observation and document analysis. The points we examined were the human resource and physical space structure and the care delivered by the shelter and by the referral health unit. We observed many deficiencies, whose solutions not only depend on the shelter, but on an articulation with other sectors, seeking a Quality health care that contemplates the needs of children and adolescents in their integrality.

Descriptors: Domestic violence; Children; Adolescents; Institutionalization; Health.

\section{RESUMEN}

La finalidad de este artículo fue describir la atención en salud ofrecida a los niños y adolescentes abrigados en el Centro de Atención al Niño y al Adolescente Victimizados (CACAV), en la ciudad de Ribeirão Preto-SP, Brasil. El estudio es descriptivo y exploratorio. Los datos fueron recolectados mediante entrevista semiestructurada, observación no estructurada y análisis documental. Los puntos Que investigamos fueron las estructuras de recursos humanos y del espacio físico del abrigo y la atención en salud prestada por el abrigo y por la unidad de salud de referencia. Observamos muchas deficiencias, cuyas soluciones dependen no solamente del abrigo, pero si de una articulación con otros sectores, buscando una atención en salud de cualidad, Que contemple las necesidades de los niños y adolescentes en su integralidad.

Descriptores: Violencia doméstica; Niños; Adolescentes; Institucionalización; Salud. 


\section{INTRODUÇÃO}

A violência doméstica contra crianças e adolescentes é uma realidade inegável, sendo responsável por altas taxas de morbimortalidade, apresentando-se, portanto, como um grave problema de saúde pública em nosso país, não podendo deixar de ser reconhecida e entendida como um fenômeno, articulado a violência estrutural e social a Que os sujeitos, suas famílias e a sociedade em Que vivem estão expostos.

O fenômeno da violência doméstica não pode ser explicado por um modelo teórico Que considere uma abordagem determinista ou única sobre o problema. As políticas de prevenção ou intervenção nesta área provavelmente terão maior êxito se conseguirmos analisar e compreender esta problemática confrontando diferentes modelos e considerando os múltiplos fatores da sua determinação(l).

Podemos analisar a violência contra a criança através dos processos de vitimação e vitimização. A vitimação refere-se aos prejuízos e abusos Que incidem sobre as classes populares, sendo resultado da própria estrutura social vigente. São crianças e adolescentes vitimados pela fome, por ausência de abrigo ou habitação precária, por falta de escolas, por exposição a doenças infecto-contagiosas. Já o fenômeno da vitimização refere-se à violência diretamente imputada, seja pelos pais, parentes ou professores, diz respeito à violência nas relações interpessoais adulto-criança, atingindo, assim, todas as classes sociais, uma vez Que, esta vivendo num mundo determinado e comandado por adultos se vê submetida ao poder do adulto e às relações de hierarQuia ${ }^{(2)}$.

Considerada como uma instituição sagrada e legítima, a família, como toda instituição social, apresenta características enQuanto núcleo afetivo, de apoio e solidariedade, apresentando também, a imposição normativa através de leis, usos e costumes, Que podem implicar em formas e finalidades rígidas de educação e relacionamento. E muitas vezes, podendo se tornar elemento de coação social, geradora de conflitos e ambigüidades a exemplo da violência doméstica.

Evidenciamos Que inúmeras crianças e adolescentes permanecem convivendo com a negação de seus direitos e valores universais, ou seja, a liberdade, a igualdade e a vida, característica de sociedades como a nossa, onde a desigualdade social é profundamente marcada entre a classe mais rica e a mais pobre e, portanto pela dominação de uma pela outra e pela violência Que ocorre nas relações interpessoais entre o adulto e a criança.

Dados apontam Que a violência doméstica no Brasil, é expressiva, devendo ser encarada como prioridade na agenda das políticas sociais. No período de 1996 a 2006, segundo dados do Instituto de Psicologia da USP, Laboratório de Estudos da Criança (LACRI) foi registrado uma incidência de 148.040 casos de violência doméstica contra à criança ${ }^{(3)}$.

A violência determina sentimentos como o desamparo, o medo, a culpa, a raiva, baixa auto-estima Que, não podendo ser manifestados, transformam-se em comportamentos distorcidos, perpetuando-se por gerações indefinidamente. Isso porque vivemos em uma cultura em Que bater nos filhos sempre foi e, infelizmente continua sendo, um direito reconhecido dos pais, para o bem dos filhos ${ }^{(4)}$.

De acordo com o Estatuto da Criança e do Adolescente (ECA), se os direitos da criança e do adolescente forem ameaçados ou violados por meio de QualQuer forma de violência, pode-se adotar, como medida de proteção à vítima, o abrigamento em uma entidade $^{(5)}$. Contudo, devemos considerar o fato de Que o abrigamento promove o rompimento de todas as relações e a perda de vínculos com a família, comunidade e demais grupos sociais.

Dessa forma, durante o tempo de permanência no abrigo, as crianças/adolescentes precisam receber toda a assistência necessária, como alimentação adeQuada, educação, assistência à saúde, carinho, compreensão e liberdade, no sentido de oferecerIhes tudo o Que foi negado ou negligenciado no ambiente familiar.

Diante dessas considerações, esta pesQuisa delineou-se com o objetivo de descrever a assistência em saúde oferecida pelo Centro de Atendimento à Criança e ao Adolescente Vitimizados (CACAV), no município de Ribeirão Preto-SP.

\section{METODOLOGIA}

A presente investigação trata-se de uma pesQuisa descritiva e exploratória, realizada a partir de uma abordagem Qualitativa, aQui compreendida como uma alternativa metodológica Que nos possibilitará construir coletivamente um novo conhecimento, ajudando-nos a entender a realidade expressa pelos sujeitos, as significações e relações Que atribuem aos fenômenos e a compreender o sentido atribuído ao objeto de estudo ${ }^{(6)}$.

O campo de estudo delineou-se junto ao CACAV, instituição de gestão municipal, ligada à Secretaria da Cidadania e Desenvolvimento Social do município de Ribeirão Preto-SP, Que atende a crianças e adolescentes vitimizados com idade entre 03 e 17 anos. A inclusão de uma criança ou adolescente no CACAV constitui uma medida provisória e excepcional, utilizada como forma de transição, até Que os órgãos judiciais definam o destino da criança ou adolescente.

O presente estudo integra o Projeto Temático FAPESP 2003/ 13966-9 "A Criança e o Adolescente Alvos de Atos Violentos ou Vítimas Potenciais da Violência”, e tem como objetivo descrever a assistência em saúde oferecida às crianças e adolescentes abrigados no CACAV. O projeto de pesquisa do Qual se insere este estudo foi analisado e aprovado pelo Comitê de Ética em Pesquisa da Escola de Enfermagem de Ribeirão Preto - USP, pela Secretaria Municipal da Cidadania e Desenvolvimento Social de Ribeirão Preto e com o consentimento dos sujeitos da pesquisa, manifestado por meio da assinatura no Termo de Consentimento Livre e Esclarecido, de acordo com a Resolução 196/96 do Conselho Nacional de Saúde.

Os dados foram coletados por meio de entrevistas semiestruturadas, observação não estruturada e análise de documentos e registros: cartões de vacinação das crianças e adolescentes abrigados e prontuários médicos existentes na instituição.

De acordo com a regionalização do sistema de saúde local, a unidade responsável pelo atendimento na região onde o CACAV está localizado é o Centro de Saúde Escola (CSE) do Ipiranga, uma unidade de nível primário, pertencente ao Distrito do CSE Cuiabá, o Qual se caracteriza, como uma unidade de atendimento de nível secundário, ligada à Faculdade de Medicina de Ribeirão Preto da Universidade de São Paulo.

Os sujeitos do estudo foram profissionais Que detêm os atributos relacionados ao Que nos propusemos a analisar, profissionais Que atuam junto ao abrigo e assistem diretamente às crianças e aos adolescentes e em número suficiente para Que se possa ter reincidência das informações. Iniciamos as entrevistas em horários variados com os funcionários da enfermagem do período diurno (2), 
seguindo-se a coordenadora geral (1), os encarregados (3) e educadores (12), e por último o técnico de enfermagem do período noturno (1), totalizando 19 funcionários entrevistados. Os sujeitos da peseuisa foram identificados por letras, sendo $\mathrm{C}$ o coordenador; $\mathrm{Pl}, \mathrm{P} 2$... (e assim sucessivamente) os profissionais de enfermagem; El, E2 ... os educadores e F1, F2 ... os encarregados.

O roteiro para as entrevistas contou com três Questões abertas e norteadoras por meio das Quais procuramos conhecer, Quantos, Quais e Qual a formação dos profissionais Que atuavam no abrigo? Como se dava o atendimento das crianças e adolescentes com relação aos problemas de saúde dentro do abrigo? Onde e como estes atendimentos eram registrados? Como era o atendimento e o relacionamento com a unidade de saúde responsável pela assistência às crianças e adolescentes abrigados?

A partir da coleta de dados e para a discussão destes, agrupamos os seguintes tópicos para melhor compreensão do nosso objeto de estudo, ou seja, a assistência em saúde oferecida às crianças e adolescentes abrigados:

A) Estrutura de recursos humanos do CACAV.

B) Estrutura do espaço físico do abrigo.

C) Assistência em saúde prestada pelo abrigo e pela unidade de saúde de referência.

\section{RESULTADOS E DISCUSSÃO}

Para melhor apreender os resultados obtidos na pesquisa, dividimos os dados em tópicos, conforme mencionado na metodologia.

\section{A - Estrutura de Recursos Humanos do CACAV}

O número total de funcionários do abrigo por ocasião da pesQuisa era de 37, além de contar com 07 estagiários, sendo eles, 01 auxiliar de enfermagem, 01 técnico de enfermagem, 06 auxiliares de serviços e limpeza sendo Que 0 I exercendo funções inerentes aos profissionais de enfermagem, 02 auxiliares de cozinha, 04 atendentes infantojuvenis, 02 agentes comunitários, 09 auxiliares de serviço e, 04 seguranças, 03 motoristas, 01 coordenador (formação em pedagogia), 01 coordenador administrativo contratado, 01 psicóloga, 01 assistente social e 0 I terapeuta ocupacional.

Com relação aos profissionais de enfermagem, observamos a presença de um funcionário sem formação específica. Este foi contratado como auxiliar de serviços, mas é responsável por acompanhar os abrigados ao serviço de saúde, agendar consultas e administrar medicamentos; lida exclusivamente com as Questões de saúde, sendo referido, pelos demais funcionários, como um "profissional da enfermagem".

No Que se refere à formação, destacamos como esta interfere nas atividades realizadas pelos encarregados e educadores. Notamos Que, em geral, aqueles com formação superior ou magistério possuem uma postura diferenciada, demonstrando maior dedicação e interesse pelo trabalho, satisfação e paciência no exercício de suas funções.

Consideramos relevante esclarecer como se organizam alguns dos profissionais no exercício de suas funções, para melhor entendermos como eles se relacionam com a saúde das crianças e adolescentes abrigados.

No período diurno, os serviços de enfermagem são exercidos por uma auxiliar de enfermagem e uma auxiliar de serviços, Que trabalham de segunda a sexta, das 7 às 17 horas. Já no período noturno, há um técnico de enfermagem Que trabalha as segundas, Quartas e sextas-feiras. Nos demais dias suas funções são exercidas pelos encarregados e pelos educadores.

Os educadores são funcionários Que permanecem em tempo integral com os abrigados; são responsáveis pelo cuidado das crianças e adolescentes. Auxiliam na alimentação, no banho, no horário de dormir, nas lições escolares, tentam manter a ordem e evitar brigas, e, como descreveremos adiante, muitas vezes administram medicamentos, acompanham as crianças em consultas médicas, etc. Uma grande dificuldade referida pelos entrevistados é alta rotatividade dos profissionais:

“Às vezes não é possível fechar o mês sem Que ocorram mudanças. Isso ocorre principalmente pela inadaptação dos funcionários ao serviço ou por Questões políticas, como cortes para contenção de gastos, mudanças de secretariado e indicações de novas pessoas para ocuparem os cargos, além da contratação de funcionários não concursados por indicação política. É muito difícil manter a organização dos serviços, pois sempre há funcionários novos, muitas vezes despreparados, Que necessitam de tempo para adaptação" (C).

De acordo com a literatura trabalhar com a vitimização pode tocar profundamente o profissional, e originar sentimentos como negação, raiva, desconforto, projeção ou ansiedade avassaladora. A sensação de impotência e imobilismo talvez sejam os parceiros mais freeüentes dos profissionais Que atuam diretamente com crianças e adolescentes vitimizados ${ }^{(7)}$.

Uma Questão relatada é Que muitas crianças e adolescentes simulam alguns sintomas. Os funcionários acreditam Que, pela carência afetiva, Queixar-se de dor de cabeça, por exemplo, é uma forma de obter mais atenção e cuidado. Dessa forma, referem cautela e discernimento durante a administração, para evitar o uso indiscriminado de medicamentos, principalmente os analgésicos.

\section{B - Estrutura do Espaço Físico do Abrigo}

Observamos Que a instituição como um todo possui uma série de deficiências com relação ao espaço físico, o Que acaba por interferir na Qualidade de vida das crianças e adolescentes e na assistência em saúde a elas oferecida. Dessa forma, apresentamos a seguir uma breve descrição das instalações do abrigo.

O abrigo funciona em uma casa alugada pela prefeitura municipal, localizada na zona leste do município de Ribeirão Preto. O imóvel é bastante antigo e não apresenta infra-estrutura adeQuada para o funcionamento de uma instituição com as peculiaridades de um abrigo. Além disso, localiza-se em uma avenida extremamente movimentada, sem as condições de segurança necessárias.

O prédio conta com uma recepção, a Qual se caracteriza como única via de acesso para o interior do abrigo. Nesta sala estão dispostos computador, impressora, armário de documentação do abrigo e armário de medicações. O entrevistado C se Queixa da inadequação deste local, pois objetos de extrema importância são armazenados em um ambiente inseguro e expostos ao público. Quanto aos medicamentos Que são dispostos neste espaço do abrigo, encontramos drogas de diversas classes farmacológicas, 
utilizados pelas crianças e adolescentes, desde analgésicos como dipirona e paracetamol até drogas de controle rigoroso, como carbamazepina e outras drogas psieuiátricas e neurológicas. Esses medicamentos são armazenados em um armário, Que permanece trancado, sendo responsabilidade dos auxiliares de enfermagem e dos encarregados abri-lo Quando necessário.

A sala de atendimento é, na verdade, utilizada para muitas finalidades. É o local onde trabalham e atendem os coordenadores, assistente social e psicólogo. Além disso, acabou tornando-se um local de depósito de materiais, devido à falta de espaço. A garagem tornou-se um espaço utilizado para várias atividades. Nela as crianças e adolescentes assistem televisão com hora marcada e limitada, alguns estudam, outros brincam.

$\mathrm{O}$ espaço destinado às crianças do jardim atende aos abrigados com idade entre 2 e 6 anos, teoricamente. Contudo, devido à falta de espaço no infanto-juvenil, crianças com idade até 8 anos têm permanecido no jardim. É um Quarto único, com I I leitos, com uma janela Que se abre para a frente do prédio, facilitando a saída para a rua.

Outro problema existente era a falta de espaço para os abrigados estudarem e cumprirem as lições de casa. Dessa forma, Quintal dos fundos e a garagem foram transformados em uma sala de estudos, havendo, contudo, limitação de espaço para lazer das crianças do jardim. Estas se apresentam visivelmente estressadas por permanecerem praticamente o dia todo no interior do abrigo.

As refeições não são preparadas no abrigo, sendo apenas servida lá, pois não há estrutura física e materiais adequados para o preparo dos alimentos. No fundo da casa há uma sala utilizada como almoxarifado, onde se misturam roupas, produtos de limpeza e materiais didáticos. Há também um banheiro para utilização dos abrigados.

O Quarto do infanto-juvenil masculino é um espaço composto por duas "alas". Em uma ala estão os meninos com idade entre 7 e 12 anos. Há capacidade para 3 leitos, mas os abrigados são 7 . Na outra ala estão os meninos com idade entre 13 e 17 anos. São 8 abrigados num espaço em Que deveria haver 5. Lembramos Que, por se tratar de um abrigo provisório, estes números podem variar. O ambiente é insalubre, com pouca ventilação e iluminação. Há um banheiro para os meninos sem as mínimas condições necessárias, com instalações elétricas antigas e fios expostos e de fácil acesso aos abrigados. Há um único chuveiro para todos, o que gera grandes dificuldades no horário do banho.

A estrutura do Quarto e banheiro feminino é idêntica a do masculino. A diferença notável é Quanto à limpeza, já @ue as meninas têm uma maior preocupação com as condições de higiene.

A vigilância sanitária do município já esteve muitas vezes no abrigo para a realização de inspeções. A última vistoria ocorreu no mês de agosto de 2004, sendo detectadas diversas irregularidades. Contudo a vigilância sanitária é um departamento da própria prefeitura, a Qual mantém o abrigo neste local, com tantas irregularidades. Dessa forma, realiza-se uma denúncia da prefeitura contra ela mesma. $\mathrm{O}$ resultado é Que nenhuma providência é tomada no sentido de sanar estes problemas do abrigo, não havendo a Quem recorrer.

\section{C - Assistência em Saúde Prestada pelo Abrigo e pela Unidade de Saúde da Área}

A administração dos medicamentos é uma Questão Que divide opiniões entre os funcionários do abrigo, além de observarmos grande desorganização. A coordenação acredita Que o serviço de enfermagem do período diurno não deveria ter essa responsabilidade, afirmando Que se fossem executar essa função haveria uma sobrecarga, sendo Que outras tarefas, consideradas prioritárias, seriam deixadas de lado. Nesse sentido, a principal função da enfermagem seria buscar articulação com outros serviços, com o objetivo de ampliar o campo de assistência à saúde das crianças e adolescentes. Foi coneuista da enfermagem, neste campo, a possibilidade de assistência odontológica semanalmente, agendamento de consultas em várias especialidades médicas (oftalmologia, neurologia, ginecologia), realização de exames diagnósticos de alta complexidade, como tomografia computadorizada e ressonância magnética no Hospital das Clínicas, além de tratamento psicoterápico.

Notamos Que a administração de medicamentos acaba por ser feita por Quem está "disponível" no momento. Constatamos Que, em geral, os funcionários consideram a administração de medicamentos uma tarefa muito simples e rotineira, Que pode ser executada de Qualeuer forma, por QualQuer pessoa. Não consideram a importância do procedimento, talvez por não compreenderem sua complexidade.

“Ah, é uma coisa simples de se fazer, é só dar o remédio e pronto, é coisa que a gente faz em casa mesmo" (FI)

Alguns, porém, acreditam Que esta função deveria ser executada exclusivamente pela enfermagem. Referem insegurança pela falta de conhecimento farmacológico e dúvidas Quanto às dosagens e possíveis efeitos adversos.

"É um assunto muito sério, de muita responsabilidade. Às vezes a gente fica em dúvida se aquela é a medida certa e não tem ninguém pra perguntar" (E4).

“Às vezes a criança pode ter alguma coisa por causa do remédio e a gente não sabe" (E4)

Além disso, os educadores sentem dificuldades em administrar os medicamentos no horário correto, pois realizam muitas outras tarefas, e pela sobrecarga acabam se esQuecendo.

"É banho pra dar, é horário de janta, a gente interte em outras atividades e acaba esquecendo" (E2)

A administração segura de medicamentos é uma responsabilidade da equipe de saúde, e sua atribuição esta claramente definida em especial a equipe de enfermagem (enfermeiros, técnicos e auxiliares). Apesar dos benefícios Que proporcionam, os medicamentos podem ter sérios efeitos colaterais ou potenciais para causarem efeitos danosos Quando administrados de forma imprópria. Conhecer a responsabilidade atribuída ao profissional na terapia medicamentosa é fundamental para a conscientização da responsabilidade técnica, ética, moral e profissional $^{(8)}$.

Dessa forma, notamos Que a administração de medicamentos é uma Questão Que exige julgamento crítico dos responsáveis por esta função, para garantir a segurança dos abrigados. 
Há profissionais dedicados não só com a Questão da saúde das crianças e adolescentes abrigados, mas em todas as atividades Que realizam no abrigo. Contudo, observamos profissionais totalmente insatisfeitos e infelizes, o Que acaba refletindo num exercício desinteressado de suas funções.

Ao analisarmos os cartões de vacinação, observamos Que nem todos os abrigados possuíam tal documento na instituição. Este fato deve-se principalmente a dois fatores: em primeiro lugar, ao serem abrigadas, as crianças e adolescentes devem vir acompanhados de sua documentação, como registro de nascimento, registro geral e cartão de vacinação. Contudo, muitos pais negamse a entregá-los, pois temem Que seus filhos sejam levados à adoção; acreditam nos documentos como uma garantia de "posse" dos filhos. Além disso, um segundo fator, é a alta rotatividade no abrigo, muitas crianças ou adolescentes ficam abrigados por poucos dias, não havendo tempo suficiente para obter sua documentação. Dessa forma, as carteiras de vacinação Que conseguimos consultar são, em sua maioria, dos abrigados Que estão na instituição há mais tempo.

Observamos Que 40 abrigados possuíam algum tipo de documentação neste arQuivo, mas apenas 26 carteiras de vacinação estavam disponíveis. Dos 26 cartões analisados, detectamos Que apenas 01 estava irregular. $\mathrm{O}$ reforço das vacinas sabin e tríplice bacteriana encontrava-se em atraso há 28 dias. A criança era do sexo feminino e tinha 05 anos de idade.

Com relação à vacinação, notamos Que a atenção dispensada pelo abrigo é satisfatória, pois a maioria das crianças e adolescentes estavam com suas vacinas em dia, com exceção do caso descrito acima.

Vale ressaltar Que a i imunização, particularmente na infância, é uma das estratégias de prevenção mais significativas. No mesmo nível de importância da imunização, são colocadas como medidas de proteção e promoção da saúde infantil, a amamentação, o acompanhamento do crescimento e desenvolvimento, o tratamento precoce da diarréia infantil, a diminuição dos índices de morbimortalidade, o estimulo do apego mãe-filho-família, a organização do seguimento infantil, a capacitação de recursos humanos, o autocuidado e a cidadania ${ }^{(9)}$.

\section{C.I - Prontuários médicos}

Os chamados "prontuários médicos" são individuais e não contêm informações sobre a condição ou evolução do Quadro de saúde dos abrigados, funcionando apenas como uma pasta de areuivo de documentos antigos, relacionados à saúde das crianças e adolescentes. Neles são armazenados os receituários médicos, resultados de exames por imagem e laboratoriais, fichas de controle de medicamentos, constituindo uma espécie de histórico. Quando as crianças e adolescentes são desabrigados os prontuários são encaminhados à Secretaria Municipal da Cidadania e Desenvolvimento Social, juntamente com os demais documentos, para compor o areuivo do abrigado.

Durante as entrevistas observamos Que os educadores não manipulam estes arquivos, sendo Que muitos nem sabiam de sua existência. Os responsáveis pela manipulação destes "prontuários" são os encarregados, os profissionais de enfermagem e a coordenação geral.

Outra forma de registro disponível no abrigo é o chamado "diário de bordo". É um livro utilizado para registro de Queixas e condutas. Se o abrigado apresentou cefaléia, por exemplo, este fato é anotado, sendo também descrita Qual a providência tomada, se foi medicado, se foi encaminhado ao serviço de saúde ou se outra providência foi tomada. Dessa forma, este livro é o Que de fato mais se aproxima de um prontuário clínico. Contudo, ele não é individualizado, sendo Que as Queixas de todos os abrigados são descritas conjuntamente, por Qualeuer profissional.

O registro é definido como Qualeuer material escrito ou impresso Que é deixado como documento de prova para pessoas autorizadas. Deve abranger o estado de saúde e as necessidades da pessoa, assim como os serviços prestados. Um bom registro não reflete apenas na Qualidade do cuidado, mas também evidencia a responsabilidade na prestação deste cuidado.

\section{C.2 - Atendimento/ Relacionamento com a Unidade de Saúde}

A relação com CSE do Ipiranga é descrita pelos entrevistados de forma positiva. Referem ter abertura e facilidade de comunicação, não apresentando dificuldades para agendar consultas; as emergências são atendidas imediatamente.

Ao serem interrogados sobre o atendimento na unidade de saúde, todos os funcionários do abrigo disseram que o atendimento era "bom". Contudo, ao investigarmos mais detalhadamente, constatamos uma série de deficiências, conforme relatado a seguir.

Um dos problemas relatados por todos os funcionários é a demora no atendimento. Entretanto, estes consideram essa demora normal, e têm consciência de Que este é um problema do sistema de saúde brasileiro, Que acomete todos ou Quase todos os serviços públicos de saúde. O maior problema acarretado por esta demora é Que os educadores, funcionários Que normalmente acompanham os abrigados aos serviços de saúde, deixam seu trabalho no abrigo, havendo sobrecarga para aQueles Que irão suprir sua ausência.

Além disso, os educadores sentem, em muitas consultas, preconceito por parte dos profissionais de saúde, além da falta de paciência. Acreditam Que, por se tratar de crianças e adolescentes vitimizados, já carregam consigo o estigma de bagunceiros, rebeldes.

“Quando a gente chega eles (profissionais de saúde) já vão falando: fica Quieto, sem fazer bagunça. Eles acham que as crianças são tudo sem educação só porQue é do abrigo" (E2)

Referem, ainda, Que as consultas são pouco detalhadas, resolvendo apenas o problema emergencial. Não há um serviço de prevenção, tão pouco de promoção da saúde. Além disso, a relação com os profissionais de saúde, especialmente os médicos, e o horário de atendimento noturno, é apontada de forma crítica e negativa:

“Os médicos nem põe a mão na criança, fica tudo de longe (...) se o problema é dor, dá dipirona, se tem alguma infecção, dá diclofenaco, e se precisa de antibiótico e amoxicilina. É só isso Que eles sabem fazer" (EII)

"Acho que o pessoal Que trabalha à noite fica muito estressado, atende a gente com um mau humor, uma má vontade. É uma 
falta de respeito com a gente. Nós também trabalhamos à noite, nem por isso trata os outros com tanta falta de respeito" (EI2)

Percebemos, portanto, Que na assistência prestada pelas unidades de saúde ainda predomina o modelo biológico, médico centrado, não evidenciando aspetos relacionados a continuidade, longitudinalidade e integralidade da assistência ${ }^{(10)}$. A assistência fundamenta-se, sobretudo na "Queixa-conduta", ou seja, a criança ou o adolescente tem uma Queixa e vai a UBS somente diante da Queixa apresentada, para ter um problema resolvido, sem nenhum investimento nas causas do problema, além de não se investir em ações de promoção e prevenção. Centra-se nos aspectos clínicos, sem considerar o contexto social, econômico e cultural em Que estas crianças e adolescentes estão envolvidos ${ }^{(9)}$.

Estabelecer uma nova relação entre as áreas da Assistência Social, do Judiciário e da Saúde em especial da enfermagem, na busca de práticas, principalmente as Que reportem à atuação conjunta junto à criança e ao adolescente vitimizados, à sua família, ao abrigo e a comunidade è o movimento presente que se faz necessário. Busca-se um trabalho intersetorial e um cuidado integral considerando-se as necessidades próprias de cada região, de cada família, de cada criança e de cada adolescente, numa prática mais humanizada, resolutiva, como uma forma de promoção da vida, de expressão do ser e de resistência para sobreviver ${ }^{(1)}$.

Finalmente, todas as propostas, ações, discussões, Que visem à assistência à saúde da criança e do adolescente vitimizados, além de considerar o descrito acima, deverão pautar-se na consciência de que trabalhamos com um sujeito particular. Devemos deslocar o foco do risco e do assistencialismo para a promoção de desenvolvimento saudável da criança, sem reproduzir a cadeia de exclusão, fortalecendo assim as bases de apoio, elementos fundamentais Que compõem os alicerces do desenvolvimento integral da criança, ou seja, os recursos familiares e comunitários Que oferecem segurança física, emocional e afetiva as crianças e aos adolescentes ${ }^{(12)}$.

\section{CONSIDERAÇÕES FINAIS}

Nosso objetivo, nesse estudo, foi descrever a assistência em saúde oferecida pelos profissionais do CACAV às crianças e adolescentes abrigados.

Com relação à estrutura de recursos humanos, notamos Que os profissionais mais diretamente envolvidos com as Questões de saúde estudadas são a coordenadora geral, os profissionais de enfermagem, os encarregados e os educadores. Os educadores e encarregados com formação superior ou magistério possuem, em geral, uma postura diferenciada, demonstrando maior dedicação e interesse pelo trabalho, satisfação e paciência no exercício de suas funções.

Quanto ao espaço físico, notamos muitas inadeQuações, faltando apenas sensibilização e mobilização dos órgãos competentes para o desenvolvimento de uma estrutura mais adequada, com o fim de se promover uma melhor Qualidade de vida para as crianças e adolescentes.

No Que se refere à vacinação, constatamos Que a atenção dispensada à regularidade das vacinas é satisfatória, pois apenas uma entre 26 crianças estava em atraso, sendo este nos reforços da Sabin e da tríplice bacteriana. Os "prontuários médicos" não contêm informações sobre a condição ou evolução do Quadro de saúde dos abrigados, funcionando apenas como uma pasta de arouivo de documentos antigos, relacionados à saúde das crianças e adolescentes.

Quanto ao atendimento e à relação com as unidades de saúde, notamos Que os abrigados possuem bom acesso às consultas médicas, mas neste atendimento, ainda predomina o modelo médico centrado, sem considerar o contexto social, econômico e cultural em Que as crianças e adolescentes estão envolvidos.

Sabemos Que a saúde dos abrigados não se limita a estas Questões básicas Que nos propusemos a estudar. Contudo, consideramos importante refletirmos sobre estes pontos Que apresentaram tantas deficiências, muitas das Quais não envolvem apenas o CACAV e seus funcionários, mas também o modelo de gestão municipal e a formação dos profissionais. No Que tange a este aspecto, considerando a enfermagem, vislumbramos uma urgente necessidade da inclusão da temática violência nos currículos dos cursos de enfermagem tanto do nível médio como superior, a fim de ampliarmos o conhecimento e a Qualificação dos profissionais frente a esta problemática.

Pudemos identificar Que a dificuldades enfrentadas pelos profissionais para acolher e atender as crianças e os adolescentes no tocante as necessidade de saúde ainda pauta-se na dificuldade de integração com a área da saúde. A intersetorialidade no enfrentamento deste desafio é a mudança substancial Que se apresenta. A atuação frente à violência e a assistência às crianças e adolescentes abrigados não deve estar apenas nas mãos dos serviços de segurança pública, judiciário e assistência social, e sim se integrar entre os diferentes segmentos da sociedade civil e setores governamentais. A área da saúde deve tomar para si um dos mais importantes papéis nesta nova época, participar de forma efetiva na identificação, assistência e prevenção da violência doméstica.

\section{REFERÊNCIAS}

I. Romeu G, Deslades SF, Veiga MM, Bhering C, Santos JFC. Por Que as crianças são maltratadas? Explicações para a prática de maus-tratos infantis na literatura. Cad Saúde Pública 2002; 18(3): 707-14.

2. Azevedo MA, Guerra VNA. Crianças Vitimizadas: A Síndrome do peQueno poder. São Paulo (SP): Iglu; 1989.

3. Instituto de Psicologia da USP. Laboratório de estudos da criança. [citado em: 0I fev 2007]. Disponível em: URL: http:/ /www.lacri.usp.br
4. Azevedo MA, Guerra VNA. Mania de bater: a punição corporal doméstica de crianças e adolescentes no Brasil. São Paulo (SP): Iglu; 2001.

5. Ministério da Justiça (BR). Estatuto da Criança e do Adolescente. Lei 8069 de 13 de Julho de 1990. São Paulo (SP): Forja; 1991.

6. Minayo MCS. O desafio do conhecimento: pesquisa Qualitativa em saúde. São Paulo (SP): HUCITEC/ABRASCO; 1996. 
Ferriani MGC, Bertolucci AP, Silva MAI.

7. Camargo CL. Violência contra crianças e adolescentes. Acta Paul Enferm 2000; 13: 167-70.

8. Coimbra IAH, Cassiani SHDB. Responsabilidade da enfermagem na administração de medicamentos: algumas reflexões para uma prática segura com Qualidade de assistência. Rev Latino-am Enfermagem 200 I; 9(2): 56-60.

9. Figueiredo GLA, Mello DF. A prática da enfermagem na atenção à saúde da criança em unidade básica de saúde. Rev Latinoam Enfermagem 2003; I I (4): 544-5 I.
10. Starfield B. Atenção Primária: equilíbrio entre necessidades de saúde, serviços e tecnologia. Brasília (DF): Ministério da Saúde; 2002.

1 I. Silva AL, Vogel C, Virgílio MS. Significados de cuidado para crianças e adolescentes vítimas da violência doméstica. Rev Bras Enferm 200 I; 54(I): 48-62.

12. Rizzini I, Barker G, Cassaniga N. Criança não é risco, é oportunidade - fortalecendo as bases de apoio de familiares e comunitárias para crianças e adolescentes. Rio de Janeiro (RI): Ed. Universitária - Instituto Promundo; 2000. 